\title{
La construcción social del heredero en Playa Mulatos: un proce- so alterno de territorialización en el litoral Pacífico colombiano
}

\author{
The social construction of the heir at Playa Mulatos: an alternative process of \\ territorialities in the Colombian pacific littoral
}

\author{
Lina María Muñoz Aristizábal \\ Universidad del Valle \\ lmunoz.aristi@gmail.com
}

\section{Resumen}

En el presente artículo se trabaja la estructura social, la familia y los parentescos en Playa Mulatos, con el propósito de comprender las estrategias de alianza para la preservación de la integridad del patrimonio, centrando el interés en aquellas relaciones que en Vigía y Mulatos se definen por elementos propios del territorio, tales como su organización y la apropiación de los recursos, los cuales se articulan en torno a los derechos de propiedad. Se analizan a lo largo del texto las estrategias de control territorial, tales como la endogamia practicada por generaciones entre las familias de herederos, las celebraciones religiosas mareñas y la práctica de la construcción naval como el arte de mayor tradición en la Playa. Estas son territorialidades que permiten evidenciar los contrastes y afirmaciones identitarias entre lugareños y llegaderos en sus intercambios culturales y materiales, que han logrado convertir en un aprendizaje mutuo posibilitando la convivencia entre ambos grupos.

Palabras clave: Proceso de territorialización, estrategias de control territorial, lugareño, llegadero.

\begin{abstract}
In this article we work on social structure, family and relationships in Playa Mulatos, with the purpose of understanding the strategies of alliance for the preservation of integrity of heritage, focusing our interest in those relationships that in Vigía and Mulatos are defined by own elements of the territory, such as their organization and appropriation of resources, which are articulated around the rights of property. The strategies of territorial control are analyzed throughout the text, such as the inbreeding practiced by generations among the families of heirs, the religious celebrations of the seas and the practice of shipbuilding as the most traditional art on the beach. These are territorialities that allow to demonstrate the contrasts and identitary affirmations between villagers and arrivals in their cultural and material exchanges, which they have managed to turn into a mutual learning making possible the coexistence between both groups.
\end{abstract}

Keywords: Process of territorialization, strategies of territorial control, villager, arrival. 


\section{Introducción}

En las investigaciones sobre la construcción del territorio en el litoral Pacífico colombiano sobresalen los procesos de negros e indígenas para la descripción y comprensión de ese universo. Autores como Oscar Almario, Juana Camacho y Eduardo Restrepo, Odile Hoffmann, Nina de Friedeman, Anne-Marie Losonczy, Nancy Motta, entre otros, han dedicado sendas investigaciones a la indagación sobre las identidades negras e indígenas en el Pacífico colombiano ${ }^{1}$.

Por su parte, Stella Rodríguez reconoce la limitación de la antropología para estudiar el caso de los núcleos de población fenotípicamente blancos que han quedado aislados de la dinámica nacional ${ }^{2}$. Para la antropóloga, la población blanca que hoy habita el litoral Pacífico ha sido excluida de los enfoques antropológicos al ser vista como carente de identidad étnica o de tradición ancestral, y simplemente se los ha incluido como parte de la sociedad nacional mestiza, de cuya dinámica, paradójicamente, han estado en su mayoría excluidos. Frente a la ausencia de tal enfoque, estos grupos blancos, han sido vistos desde una perspectiva antropológica tradicional, que ha hecho énfasis en resaltar la identidad a partir de particularidades únicas que evidencian marcadas diferencias con los otros grupos que habitan el territorio, dejando de lado la influencia que las relaciones de interdependencia mutua, establecidas entre las diversas poblaciones, tienen en la construcción de su identidad. Según Rodríguez, tampoco se ha entrado a profundizar en las formas de integración identitarias propias

1 Oscar Almario y Ricardo Castillo, "Territorio, poblamiento y sociedades negras", en Renacientes del Guandal. "Grupos negros" de los ríos Satinga y Sanquianga (Medellín: Ministerio del Medio Ambiente, Universidad Nacional de Colombia, 1996); Juana Camacho y Eduardo Restrepo, De montes, ríos y ciudades. Territorios e identidades de la gente negra en Colombia (Bogotá: Fundación Natura, Ecofondo, Instituto Colombiano de Antropología, 1999); Odile Hoffman, "Territorialidades y alianzas: construcción y activación de espacios locales en el Pacífico", en De montes, ríos y ciudades. Territorios e identidades de la gente negra en Colombia, eds. Juana Camacho y Eduardo Restrepo (Bogotá: Fundación Natura, Instituto Colombiano de Antropología, Ecofondo, 1999); Odile Hoffman, "La movilización identitaria y el recurso a la memoria (Nariño, Pacífico colombiano)", en Memorias hegemónicas, memorias disidentes, eds. Cristóbal Gnecco y Marta Zambrano (Popayán: ICANUniversidad del Cauca, 2000); Anne-Marie Losonczy, "Memorias e identidad: los negro-colombianos del chocó", en De montes, ríos y ciudades. Territorios e identidades de la gente negra en Colombia, eds. Juana Camacho y Eduardo Restrepo (Bogotá: Fundación Natura, 1999); Nancy Motta González, Por el monte y los esteros. Relaciones de género y familia en el territorio afropacifico (Cali: Pontificia Universidad Javeriana, 2002); Homi Bhabha, "El entre-medio de la cultura", en Cuestiones de identidad cultural, comps. Stuart Hall y Paul du Gay (Buenos Aires - Madrid: Amorrortu Editores, 1996); Peter Burke, Formas de historia cultural (Madrid: Alianza Editorial, 2000); Luis Carlos Castillo, "La construcción de la identidad del otro: poder y resistencia", en Etnicidad y nación. El desafio de la diversidad en Colombia (Cali: Programa Editorial Universidad del Valle, 2009).

2 Stella Rodríguez, "Libres y culimochos: ritmo y convivencia en el Pacífico Sur colombiano", en Afrodescendientes en las Américas: trayectorias sociales e identitarias, eds. Claudia Mosquera, Mauricio Pardo y Odile Hoffmann (Bogotá: Universidad Nacional de Colombia, ICANH, IRD, ILAS, 2002). 
de los vigieños y mulateños herederos que han participado en la configuración de este territorio en el Pacífico Sur colombiano.

En consecuencia, el conocer los procesos de territorialización de los vigieños y mulateños supone la aproximación a procesos alternos desarrollados en el Pacífico colombiano y, por tanto, una perspectiva ampliada al respecto que reconozca una mayor diversidad. Este esfuerzo investigativo sobre Playa Mulatos propone, entonces, un cuestionamiento al imaginario de Pacífico Sur colombiano que se ha construido en parte desde la academia, en parte desde el Estado.

Los vigieños y mulateños han sido un grupo humano con una organización propia dada sobre una playa de propiedad proindivisa. Para este trabajo centramos el interés en aquellas relaciones que en Playa Mulatos se definen por elementos propios del territorio tales como su organización y la apropiación de los recursos, los cuales se articulan en torno a los derechos de propiedad. Estas identidades que se construyen propiamente en relación con el territorio han sido objetos/sujetos de estudio en varias de las poblaciones negras e indígenas del litoral Pacífico colombiano, no obstante, solo un puñado de ellas centra su atención en Vigía y Mulatos.

Playa Mulatos es una triada de playas - Vigía, Mulatos y Amarales- que se encuentran ubicadas al norte del Pacífico nariñense. Los vigieños y mulateños han sido un grupo fenotípicamente blanco con una organización propia dada sobre una playa de propiedad proindivisa que poseen legalmente desde 1782. Vigía es un corregimiento de La Tola, que hace parte de una de las tres bocanas que conforman el Parque Natural Nacional Sanquianga. A su vez, Vigía hace parte de la Subregión de Sanquianga, una de las 13 subregiones en las que se divide el departamento de Nariño. La playa de La Vigía junto con las de Mulatos y Amarales conforman un espacio que no está políticamente definido, pero que en el imaginario de sus habitantes rememora un pasado en común. Con el paso de los años el mar se devora las playas de la bocana del Sanquianga; las casas deben ser reubicadas al igual que los lugares de encuentro donde las tradiciones y su recuerdo acontecen. Muchas de esas prácticas tradicionales y particulares de los habitantes de La Vigía han logrado sobrevivir y "reubicarse" una y otra vez, permitiendo hoy la aproximación de la autora a ellas en el intento por comprender sus procesos de territorialización.

La herencia en Vigía y Mulatos funciona como forma de transmisión del patrimonio, como única forma de acceso a la tierra en Playa Mulatos. Las reglas para el acceso a la tierra por herencia se relacionan con la condición de hijo y con la muerte de los padres: todo hijo de un heredero legítimo o natural tiene derecho a heredar ${ }^{3}$. Si la mamá está viva, pero el padre muere, entonces los hijos se convierten en he-

3 Nelly Rivas, "Modalidades de acceso a la tierra en el Pacífico nariñense: río Mejicano-Tumaco", en Montes, ríos y ciudades. Territorios e identidades de la gente negra en Colombia, eds. Juana Camacho y Eduardo Restrepo (Bogotá: Fundación Natura, Instituto Colombiano de Antropología, Ecofondo, 1999), 97. 
rederos. Si los dos padres son herederos, cuando uno de los dos muera, los hijos se convertirán en herederos. Sin embargo, padres e hijos son dueños de la Playa, pero los hijos no determinan nada antes de que los padres se mueran, según la Mona Javiera, una de las mayores de la Playa, porque ellos son los que tienen que mandar. La Mona afirma que:

Aquí la tierra no se puede vender, así está en la escritura. Ni se pueden vender títulos de bienes de menores de edad, bajo el cual los hijos de un heredero, cuando este ya ha titulado sus derechos y ya tiene una casa en la Playa, no vienen a heredar nada ni pueden vender nada hasta que el heredero fallezca. Por eso dice que la Playa es "bienes de menores de edad"4.

\section{Estrategias de control territorial e integridad del patrimonio}

Las nuevas generaciones de vigieños y mulateños mantienen muy presente su condición de herederos legítimos de la Playa. Por ejemplo, son cuidadosos de legalizar su herencia y la de sus hijos, llevando a cabo un proceso similar al de un ciudadano común propietario de un territorio heredado. Una mañana de caminata entre Vigía y Mulatos, por el camino del manglar cuando aún el sol brillaba y calentaba, un heredero amigo que vive en Cali comentó, en medio de una conversación, sobre el significado de la escritura pública para ellos como herederos legítimos de la playa, que él ya había escriturado legalmente a todos sus hijos como herederos de Playa Mulatos, hijos que, aunque de distintas madres, compartían su condición de herederos al ser todos hijos de un vigieño. Este proceso legal de escrituración en documento público de los herederos legítimos de Playa Mulatos es una suerte de tradición familiar de vigieños y mulateños, quienes al escriturar sus nombres se convierten en herederos de la Playa y custodios de la escritura, pues aquellas familias que poseen una copia de esta, la guardan con mucho recelo en sus casas o con algún abogado de confianza.

La cesión de derechos herenciales está regulada en Colombia por los artículos 1857 inciso segundo, 1967 y 1968 del Código Civil, en los que se reglamenta la negociación o disposición del derecho real de herencia. Este tipo de compraventa de derechos y acciones herenciales se realiza con el ánimo de que el comprador, quien lo adquiere de manos del heredero (vendedor), reclame en lugar del heredero originario los derechos sucesorales que le correspondan en la sucesión de determinada persona, bien sea padre, madre o hermano del vendedor ${ }^{5}$.

Es pertinente resaltar que al ser Playa Mulatos una propiedad proindivisa, los herederos venden y compran acciones entre ellos y sus descendientes, trámites legales

$4 \quad$ Javiera Estupiñán Estupiñán, (Mulateña - Mulatos), entrevista personal, marzo - abril de 2011.

5 David Cadena, "Venta de derechos herenciales". Notaria 74 de Bogotá. http://notaria74bogota.co/index. php/compraventas/derechos-herenciales. 
que se han registrado en la Escritura Pública, Instrumento No.3. Por ejemplo, se dejó registro de que

en el Distrito de Iscuandé, provincia de Barbacoas, Departamento del Cauca, República de Colombia a 3 de octubre del año 1892 ante, Pimiento Castrillón, notario primero (suplente en ejercicio del Distrito No. 3) y los testigos Rafael Lemos y Leandro Obando, vecinos del mismo circuito, mayores de edad, de buen crédito y en quienes no concurre ninguna causal de impedimento, que el señor Adolfo Estupiñán compareció por sí, con su esposa Celmira Estupiñán, sus cuñados Federico, Leopoldo, María Ventura y Ana Rosa, como comprador de varias acciones en la playa de Mulatos; dos (2) a María Reina, una (1) a Mercedes Reina y otra a Carmen Estupiñán, todos descendientes legítimos de Claudio de Reina... ${ }^{6}$.

También se ha dejado constancia en la Escritura, Instrumento No.4, de la venta de la acción que pertenecía a dos hermanas Estupiñán que, al no tener hijos ni marido, deciden venderles a sus dos hermanos su acción y derecho herencial sobre la Playa de Mulatos que heredaron de su abuelo:

Nosotras, Ángela y Rosana Estupiñán, mayores de edad, solteras y vecinas del Distrito de Iscuandé, hacemos constar que hemos dado en venta real y enajenación perpetua para sí y los suyos a los señores Manuel y Adolfo Estupiñán, también mayores de edad y vecinos de este distrito, es a saber: la acción que nos corresponde en la Playa de Mulatos cita en esta jurisdicción la cual hubimos por herencia de nuestro finado abuelo materno Julián Estupiñán; la cual está pro indivisa, con otros condueños y tiene los siguientes linderos: por el Sur, Sanquianga; por el Norte, la Playa de Amarales; por el Este, el camino real de Perico; y por el Oeste, el mar; la cual vendemos por la suma de cincuenta pesos de ocho décimos que en dinero hemos recibido a nuestra satisfacción de manos de los compradores. Que no está vendida a ninguna otra persona. Está libre de censo e hipoteca. Que el verdadero valor es el de los cincuenta pesos ya expresados y si más valiese hacemos gracia y donación a los compradores. Que, en todo caso, nos obligamos a la evicción y saneamiento del terreno vendido. Que desde hoy entregamos a los compradores la cosa vendida con las acciones consiguientes y nos separamos del derecho y señorío que antes teníamos y nos sujetamos a las autoridades de la República para que nos obliguen y compelen al fiel cumplimiento del presente y renunciamos toda ley que nos pueda favorecer hasta la de domicilio y vecindad, y como no sabemos firmar, rogamos firmen por nosotras con testigos en la Playa Mulatos a quince (15) de Mayo de 1888 a ruego de las vendedoras?

6 Escritura Pública de la propiedad sobre Playa Mulatos, Instrumento No.3, 1892, Archivo de Buga.

$7 \quad$ Ibid., Instrumento No. 4. 
Los instrumentos No. 2, 3 y 4 de la Escritura son algunos de los apartes del documento legal de propiedad sobre la Playa, que evidencian el interés imperativo del grupo de herederos por asegurar la perpetuidad de la integración del patrimonio. Según Pierre Bourdieu, en este tipo de grupos que comparten un patrimonio, hay una estructura generadora de prácticas conformes con el imperativo fundamental de la perpetuación de la integridad del patrimonio. Teniendo en cuenta que prima este, cualquier instrumento que se pudiera usar con tal fin, sería lo que se decidiera ${ }^{8}$.

En nombre de preservar la integridad del patrimonio en Playa Mulatos, también se decidió crear la figura de comuneros ${ }^{9}$ para todos los descendientes de Claudio de Reina. En su calidad de codueños todos de una tierra proindivisa, entre los derechos agrarios de los que gozan, el básico de ellos es poder beneficiarse del uso y del aprovechamiento de la tierra, tanto de manera individual como en comunidad. Es así como lo anterior para el caso de Vigía y Mulatos queda consignado en la Escritura de propiedad que data de 1787 y en el documento que consolida la aparición de esta figura político-social, dando sentido a su existencia en la vida comunitaria de la Playa: "Las doce reglas de los comuneros" de $1892^{10}$.

La primera de las reglas establece que " 1 . Todo comunero legítimo de la Playa de 'Mulatos' puede hacer cualquier trabajo en dicha playa, teniendo en cuenta el derecho que le corresponda y sin perturbar los trabajos de otros comuneros", lo que les garantiza su derecho al uso y aprovechamiento de la tierra a través del trabajo. De igual forma, en este documento que dicta las doce reglas de los comuneros, se definen las formas en las que se puede adquirir el derecho a la tierra y por parte de quiénes puede ser adquirido. Al respecto, la regla número 9 dicta que

cualquier o cualesquiera de los comuneros que quiera vender la acción o acciones que tenga en el fundo de la playa de "Los Mulatos" no podrá venderlas a ninguna persona sino a los comuneros de la misma playa, no por el precio que caprichosamente quisiera vender, sino por el que justamente valgan y se revalúen por el precio que den dos peritos nombrados, uno por cada parte y un tercero nombrado por estos en caso de discordia ${ }^{11}$.

Si bien en Vigía y Mulatos no se despoja de su herencia a aquellos hijos que han decidido salir de la playa y vivir fuera de ella, sí se favorece en alguna medida a aquellos que han optado por vivir en la playa y trabajar la tierra. Así lo deja claro la regla número 11:

$8 \quad$ Pierre Bourdieu, "La tierra y las estrategias matrimoniales", en El sentido práctico (Argentina: Siglo Veintiuno Editores, 2007), 235-256.

9 Según la definición jurídica del término, comunero es la persona que tiene en común con otra un derecho o una cosa; especialmente, una heredad o hacienda.

10 Stella Rodríguez, "Piel mulata, ritmo libre: identidad y relaciones de convivencia interétnica en la costa norte de Nariño, Colombia" (tesis de pregrado, Universidad Nacional de Colombia, 2001).

Ibid. 
como los dueños de la playa de "Mulatos" son descendientes de una misma familia y todos con derecho a trabajar en ella, ningún comunero ausente, ni los que no han querido trabajar, podrán hacerle cargo alguno bajo ninguna especie y forma a los que residan y han trabajado en la referida playa ${ }^{12}$.

Teniendo en cuenta que tal como lo dispone esta regla, son los descendientes de una misma familia los que tienen derecho a heredar los derechos y acciones sobre la Playa de Mulatos, se estableció desde un principio, aunque tácitamente, la necesidad y obligatoriedad de promover las alianzas matrimoniales entre los mismos descendientes y evitar aquellas que fueran con personas ajenas a la familia, mucho más si eran de ascendencia negra.

\section{Las normas matrimoniales en la regulación del parentesco afín en Vi- gía}

Un grupo doméstico creado a partir de la unión entre descendientes de tres familias, los Estupiñán, los Salas y los Reina, llegan al acuerdo de establecer la monogamia y la endogamia como las normas matrimoniales en la regulación del parentesco afín, con el propósito de preservar el patrimonio colectivo-familiar, la posesión y disposición legales y prácticas de Playa Mulatos. Por lo tanto, no era deseable por ningún motivo una alianza matrimonial entre un mulateño o un vigieño y un negro, ni permitida la presencia de los contrayentes en la playa. Como castigo a su iniciativa individual de casarse y no asumir el matrimonio como un asunto de grupo, se desterraba a la pareja de la playa. La endogamia practicada por décadas entre el grupo socioparental que habitaba Playa Mulatos, se propuso para mantener a su grupo separado de los grupos que habitaban zonas aledañas y así evitar que sus recursos se mezclaran. Por ejemplo, su fenotipo blanco fue un recurso de mucho estatus, sobre todo en el siglo XIX; tanto, que todavía algunos de los herederos pretenden seguirlo ostentando.

Ahora bien, tanto en Vigía como en Mulatos se han dado redefiniciones del deber ser, es decir, una cosa es el universo simbólico de la endogamia y otra es lo que realmente sucede en los hogares. Teniendo en cuenta que en la realidad las relaciones son más fluidas y entrelazantes de lo que se pacta en un papel, cabe resaltar que desde hace cerca de tres décadas la exogamia se ha ido aceptando con menos resistencia, mucho más en Vigía que en Mulatos, ya que aún la mayoría de mulateños pretende por medio de la endogamia seguir manteniendo distinciones sociales, raciales, económicas y políticas entre lugareños y llegaderos.

Vigía es una población que en su gran mayoría comparte lazos de parentesco tal como un grupo de filiación bilateral. El entramado de lazos de consanguinidad y 
parentalidad afín en Vigía es inmenso. Según el mapa de filiación bilateral de las familias vigieñas, estas se establecen como familias nucleares, es decir, dos adultos socializando niños que hacen alianzas matrimoniales entre sí para seguir formando familias nucleares neolocales, pues viven en veredas de pertenencia conjunta. La monogamia de los vigieños y mulateños es una norma matrimonial escasa en el litoral del Pacífico colombiano, pues los hallazgos de profundas investigaciones como la realizada por la investigadora Nancy Motta González, muestran que solo ha sido posible encontrar el tipo de familia monogámica en las áreas urbanas de Tumaco, Guapi, Itsmina, Bahía Solano y Quibdó. Motta también afirma que "la estructura familiar poligénica es del tipo más característico del litoral del Pacífico, esta se encuentra abierta y bajo el consenso amplio de la sociedad"13.

La monogamia en Vigía se da por unión matrimonial o por una unión libre; se caracteriza por su estabilidad y son uniones que no han estado precedidas en su mayoría por la poliginia del hombre soltero, como es el caso de las comunidades negras de la zona. La familia vigieña es una familia monogámica, entendiendo esta como "la unión conyugal de una pareja cohabitando bajo un mismo techo, casados o no, con hijos y con las responsabilidades de ejercer funciones de procreación, socialización y cooperación económica" ${ }^{14}$. En este sentido, podría afirmarse que la estructura familiar monogámica-endogámica presente en Vigía constituye un hallazgo para la comprensión del Pacífico que ha sido descrito, en su mayoría, a partir de la poligamia del hombre negro y la monogamia seriada de la mujer negra. Tanto los hombres como las mujeres en Vigía son monógamos, en algunos casos seriados. No obstante, el hecho de que los hombres vigieños sean monógamos no excluye encuentros ocasionales con mujeres que conocen en los puertos debido a sus constantes travesías marítimas como navegantes. Producto de estos encuentros nacen herederos de la Playa que casi nunca llegan a conocerla o a pernoctar en ella.

Los negros le hacen constantes burlas a los vigieños y mulateños acerca de estas características diferenciadas entre ellos. Stella Rodríguez señala esta diferenciación reconocida por los negros afirmando que

"todo culimocho tiene algo de pastuso" es una expresión común para referirse a cierta "incapacidad" de ellos para comprender bromas y palabras de doble sentido. Los libres ${ }^{15}$ los consideran poco aventajados y tímidos en cuestiones relativas al amor y al sexo, hacen chistes y sátiras sobre su marcada endogamia, acusándolos además de "pecadores" por "incestuosos", poco creyentes y religiosos. Muchos libres piensan

13 Motta, Por el monte y los esteros, 56

14 Ibid., 57.

15 "Libre" es como se autodenominaron los descendientes de esclavizados, quienes mantienen viva la memoria de la lucha de sus antepasados por alcanzar la libertad a lo largo del litoral pacífico colombiano. Rodríguez, "Piel mulata, ritmo libre". 
que como castigo divino por sus "andanzas" la mar ha ido acabando con el territorio de Mulatos tal y como lo hizo con Boquerones, Domingo Ortiz, Los Reyes y como sucede en la actualidad en San Juan de La Costa, todas ellas playas pobladas por "magos" y "magas" (adjetivo usado para referirse a las personas con algún grado de retardo físico o mental o con enfermedades congénitas $)^{16}$.

\section{Lugareños y llegaderos. Relaciones de intercambio entre particulari- dades y convergencias identitarias}

Los estudios etnográficos sobre comunidades negras en el Pacífico colombiano, fundamentalmente se abordan desde dos enfoques: a) la búsqueda de un africanismo de supervivencia; y b) la constatación de deconstrucción cultural exógena que se articula con una adaptación marginal a la sociedad global ${ }^{17}$. El primer enfoque se ha centrado en resaltar su herencia ancestral africana, mientras que el segundo enfoque ha contemplado su estrategia de adaptación como una cuestión de "olvido" y flexibilización identitaria. En cualquier caso, las miradas confluyen en la afirmación de que cada grupo mantiene su identificación étnica a partir de la articulación con otros grupos y tradiciones.

Las identidades se construyen a través de la diferencia y no al margen de ella. En este sentido, la identidad solo puede constituirse en su relación con el otro. Según Stuart Hall, "la homogeneidad interna que el término identidad trata como fundacional, no es una forma natural sino construida de cierre, y toda identidad nombra como su otro necesario, aunque silenciado y tácito, aquello que le "falta"" ${ }^{18}$. Con frecuencia se hace referencia a un pasado racista en el que los negros eran rechazados de Playa Mulatos, y solo se les permitía ingresar a la playa para ayudar en las labores de la pesca u otras actividades agrícolas, pero luego los pasos de esta gente eran borrados y los vasos en los que bebían agua eran quebrados, como dicen algunos vigieños.

Según Hall, Derrida ha demostrado que la identidad siempre se basa en la exclusión de algo, al tiempo que Laclau sostiene con vigor y persuasión que "la constitución de una identidad social es un acto de poder"19. En Playa Mulatos se ha otorgado un especial reconocimiento a las familias que fueron poseedoras de recursos que los diferenciaban económica y socialmente. Por ejemplo, aquellos que fueron grandes carpinteros navales y dueños de botes, lo que les permitía tanto pescar como movilizarse hacia otros lugares $\mathrm{y}$, por lo tanto, llevar a cabo actividades de comercio y posteriormente de turismo.

Otro de los aspectos presentes en la constitución social de los herederos de Playa Mulatos ha sido el racismo. Esta ideología estuvo muy arraigada en las generaciones

$16 \quad$ Ibid.

17 Losonczy, "Memorias e identidad: los negro-colombianos del chocó".

18 Stuart Hall, "Introducción: ¿quién necesita <<identidad $>>$ ?", en Cuestiones de identidad cultural, comps. Stuart Hall y Paul du Gay (Buenos Aires - Madrid: Amorrortu Editores, 1996), 17. Ibid., 18. 
nacidas antes de la primera mitad del siglo XX; y persiste aún en aquellos silenciosos gestos que aparentemente son imprudentes, pero al final confesamente intencionales, de los hoy mayores de la playa, aquellos que todavía sienten que los llegaderos, los que no son de ahí, de algún modo han llegado a "desmejorar" sus procesos organizativos y prácticas económicas de supervivencia.

En uno de los recorridos entre Vigía y Mulatos que hicimos durante el primer viaje a Playa Mulatos en 2011, el grupo iba en esa ocasión por el monte con William Estupiñán, quien comentó:

Mi papá fue de los últimos racistas... En esta tierra había mucho racismo. Decían que los otros dañaban la raza, ni los dejaban entrar. Nosotros somos ya de los que venimos degenerando la raza. Todos éramos "ojiclaros", zarcos. Mi abuela era del color de mi mamá y tenía los ojos azules, azules ${ }^{20}$.

Don José María Estupiñán, padre de William, tiene 25 años de fallecido y, según su hijo, hasta que su papá murió todavía se daba racismo en la playa. William recordaba que "no le gustaba que yo tuviera amigos negros, y nosotros viviendo en Buenaventura... ¡imaginate! ¿Dónde iba yo a buscar a todos los rubios para andar? (risas...). Tocaba solo amigos de la familia. Todavía estaba ese pensamiento racista" ${ }^{21}$.

Los llegaderos, por su parte, serían aquellos que ingresaban a la Vigía sin ser parte de las redes familiares herederas, pero que también eran reglamentados tácitamente por el territorio y sus habitantes. Lugareños y llegaderos lograron desarrollar modos de reciprocidad cultural. En tanto los vigieños fueron aprendiendo con particular entusiasmo algunas de las prácticas culturales de los negros, los llegaderos, por su parte, adoptaron de manera fluida representaciones de los lugareños - conducta promovida por las identidades de frontera porosas construidas por los grupos negros- $y$ modos de reciprocidad económica en la medida en que el foráneo que llega a trabajar en Vigía como empelado de un vigieño, es una persona que no posee una tierra o de lo contrario no habría llegado a la playa, y que gracias a la relación laboral que entabla tiene la oportunidad de hacer uso de los recursos de extracción del territorio, entre ellos: botes, implementos de pesca, transporte marítimo y fluvial, entre otros, y lo más importante, residir en un lugar que le brinda la posibilidad de construir "definidas" territorialidades y moverse a través de ellas.

Este tipo de intercambios permitieron una convivencia no violenta e interdependiente entre lugareños y llegaderos. Gracias a estos históricos intercambios y a los discursos de reconocimiento de la alteridad que tomaron fuerza en el país y en el $\mathrm{Pa}$ cífico Sur entrada la década de los noventas, las nuevas generaciones de herederos de la Playa comenzaron a apartarse de aquellas dinámicas que concebían al negro como

20 William Estupiñán, (Vigieño - Mulatos), entrevista personal, marzo - abril de 2011.

21 Ibid. 
subalterno en todas sus formas. Por ejemplo, en el discurso de propietarios legales frente a aquellos "invasores" de su territorio - discurso que en parte se ha construido mediante esta agresión simbólica - ya no es tan exaltada la discriminación por los nuevos herederos, quienes han ido permitiendo de manera cada vez más frecuente las uniones conyugales entre lugareños y llegaderos-negros.

Ahora bien, las relaciones de intercambio en Vigía entre lugareños y llegaderos, que en su mayoría son negros, han sido una constante durante su estadía en la Playa. Hall expresa que la identificación es condicional y se afinca en la contingencia. Una vez consolidada no elimina la diferencia. La fusión total que sugiere es en realidad una fantasía de incorporación. Continúa Hall afirmando que, como todas las prácticas significantes, la identificación está sujeta al juego de la diferencia; obedece a la lógica del más de uno. Como proceso actúa a través de la diferencia, entraña un trabajo discursivo, de marcación y ratificación de límites simbólicos, la producción de "efectos de frontera"; necesita de su exterior constitutivo para consolidar el proceso ${ }^{22}$.

Las doce reglas de los comuneros han sido para Playa Mulatos la representación de su imaginario colectivo de buen comunero, de buen vecino. Al respecto de los imaginarios sociales, Bronislaw Baczko expresa que es a través de estos que una colectividad designa su identidad elaborando una representación de sí misma; marca la distribución de los papeles y de las posiciones sociales; expresa e impone ciertas creencias comunes, fijando especialmente modelos formadores como el del "jefe", el del "buen súbdito", el del "ciudadano", el del "valiente guerrero", etc. De esta forma, en el documento redactado en 1892 por las primeras familias de la Playa, no solo se define "al buen comunero", sino que además se establecen allí las formas de acceso a la tierra y el uso de los recursos ${ }^{23}$.

Es así como la comunidad de Playa Mulatos designa su identidad a partir de la construcción de un documento que le otorga una representación de sí misma. Designar su identidad colectiva es, por consiguiente, marcar su "territorio" y las fronteras de este, definir sus relaciones con los "otros", formar imágenes de amigos y enemigos, de aliados y rivales; del mismo modo, significa conservar y modelar los recuerdos pasados, así como proyectar hacia el futuro sus temores y esperanzas. En definitiva, reconocer que el saber histórico está permanentemente motivado e inspirado, y desde el hoy, ha permitido escribir la historia más reciente con una disposición democrática, es decir, ha facilitado que sean los mismos pueblos los que dejen señal de su visión del presente y del pasado. Las sociedades tienen derecho a construir su pasado y en función de él definir su identidad.

De acuerdo con lo anterior, aunque los vigieños abren fronteras y mueven algunos límites de su identidad para permitir la entrada y aprensión de nuevos saberes de

22 Hall, "Introducción: ¿quién necesita <<identidad $>>$ ?", 15.

23 Bronislaw Baczko, Los imaginarios sociales. Memorias y esperanzas colectiva (Buenos Aires: Ediciones Nueva Visión SAIC, 1999). 
los llegaderos, también mantienen fijos aquellos elementos que los caracterizan como vigieños. Estos son más numerosos que aquellos límites identitarios que los llegaderos están dispuestos a negociar como parte del intercambio. Teniendo en cuenta la flexibilidad identitaria de estos grupos poblacionales, podría pensarse que la fluidez en los intercambios entre lugareños y llegaderos, ha sido promovida por la identidad intersticial de los negros.

Dicha flexibilización les permite a los llegaderos poco a poco ir haciéndose a un lugar en Vigía, aunque nunca propio, sí propicio para su residencia y supervivencia a través de la adopción de los modos de socialización de los lugareños. Inicialmente los llegaderos arribaban a la playa en calidad de trabajadores temporales, contratados por un lugareño para la extracción de recursos pecuarios, labores de carpintería, entre otros. Con el paso del tiempo los llegaderos empezaron a aumentar en número y en tiempo de estadía en la playa, y aunque tanto lugareños como llegaderos son conscientes de que Vigía es una propiedad colectiva proindivisa, la estadía indefinida de foráneos en el territorio les ha permitido con el tiempo ir adquiriendo algunos derechos de propiedad tácitos sobre espacios colectivos, tales como, en el caso de las mujeres llegaderas, reunirse a lavar sus ropas en el pozo, único lugar público de extracción de agua para el consumo en Vigía o la participación de llegaderas y llegaderos en las fiestas y celebraciones comunitarias.

\section{Gente de mar}

Hemos revisado hasta aquí aquellas suturas que ponen en evidencia la articulación de los intercambios entre lugareños y llegaderos. Se hace entonces necesario reconocer las particularidades culturales de los vigieños y mulateños en la medida en que, por ejemplo, sus actividades productivas se diferencian de las practicadas por sus vecinos indígenas y negros.

La construcción de barcos es una de las actividades productivas de mayor tradición en Vigía y Mulatos. Durante siglos uno de los principales oficios de los mulateños y vigieños ha sido la carpintería naval. Ellos han construido grandes barcos de transporte de materiales y pasajeros. Los hombres que se dedican a este oficio son conocidos en todo el Pacífico por ser los mejores carpinteros navales. Ellos dicen que la habilidad de armadores la han aprendido de generación en generación con base en el conocimiento de los materiales como la buena madera que extraen de la selva, y los planos que han diseñado y rediseñado para mejorar sus técnicas ${ }^{24}$. Para ellos, lo más importante a la hora de construir un barco es que este sea lo suficien-

24 Paula Galeano, Gestión desde la "diferencia” en áreas protegidas y territorios étnicos (consejos comunitarios). Apuntando al dialogo entre los biótico, lo cultural y lo político. Estudio de caso en el Parque Nacional Natural Sanquianga (Pacífico Sur Colombiano) (Bogotá: Universidad Nacional de Colombia, 2005). 
temente resistente para navegar con tranquilidad por las exigentes condiciones del Océano Pacífico.

Estos hombres de mar, grandes carpinteros navales, comenzaron construyendo pequeños barcos que les permitían desarrollar actividades como la pesca, así como movilizarse por mares, ríos y esteros, las únicas vías de acceso a la Playa. Gracias a la relación que entablaron con sus herramientas de carpintería, fueron diseñando nuevos tipos de barcos que les permitían navegar mejor por las distintas aguas que los rodean. Por ejemplo, las canoas pequeñas fueron diseñadas para navegar por las riberas, mientras que los botes livianos fueron dirigidos hacia la navegación por las cuencas, y los barcos de cabotaje servían para navegar por mar abierto. Los carpinteros navales construyeron un astillero en el caserío de Mulatos en el que hijos, padres y abuelos dedicaban gran parte de su tiempo a la construcción naval. En una gran mesa extendían los planos que definían lo que sería el barco.

Lejos de ser solo rumores, los relatos sobre la construcción naval y aventuras sobre sus naves a mar abierto hacen parte de la narrativa de vigieños y mulateños. Incluso, algunos periódicos han documentado los procesos de construcción naval de mulateños y de sus proezas como navegantes conocedores de las impetuosas aguas del Pacífico. El artículo titulado "Los armadores de barcos del Pacífico"25 hace un acercamiento sobre la labor de René Estupiñán, hijo de la Mona Javiera, como carpintero naval. En Mulatos y Vigía lo conocen mejor como el "maestro de los barcos", quien comenta que aprendió el oficio de sus tíos y su abuelo, y que lo ha puesto en práctica durante 23 años ${ }^{26}$. En los inicios de la década de 1990, René construía dos barcos por año y reparaba cinco. Con el tiempo la demanda ha bajado. Las estructuras navales construidas por René, en conjunto con su equipo de constructores lugareños y llegaderos, son similares a las que se construían en los siglos XVIII y XIX; tienen la misma capacidad de camarotes para la tripulación y pasajeros, aunque las embarcaciones actuales cuentan con un motor que se importa desde Estados Unidos, mientras que en el pasado se navegaba a vela. No nos fue posible conversar con René Estupiñán, dado que falleció en 2009 en un hecho violento en altamar en el marco del tráfico de drogas a Centro y Norteamérica, aunque sí pudimos conocer de él a través de su madre.

El repertorio de infraestructura naval ha permitido que tanto vigieños como mulateños puedan dedicarse a la actividad del comercio y transporte de pasajeros hacia poblados aledaños, principalmente el puerto de Buenaventura. Los conocimientos y habilidades de navegación desarrolladas históricamente han posibilitado su incursión en el diseño de la cartografía de rutas marítimas a lo largo de todo el Pacífico. Algunos de los barcos que transitan por estas rutas son tripulados y comandados por los nativos que participaron en su construcción, por lo que han obtenido un estatus privilegiado 
que deja como réditos mejoras a sus viviendas en el caserío y, en general, mejores condiciones de vida.

\section{Vigieños y vigieñas. Relaciones complementarias en su cotidianidad}

En Vigía, las relaciones entre hombres y mujeres pueden reconocerse como diferentes y asimétricas, sin que estas características se traduzcan necesariamente en desigualdad y jerarquía ${ }^{27}$. Es, por el contrario, una igualdad potencial entre los sexos la que se observa en Vigía. Mientras ellos son quienes se dedican diariamente al oficio de la pesca, ellas centran su atención en el cuidado de los niños y el hogar. Relaciones complementarias que se sostienen en un esfuerzo compartido de las responsabilidades para una vida digna, pues ninguno de los dos se excluye automáticamente de las actividades realizadas frecuentemente por el otro. Por ejemplo, cuando los hombres no están afuera pescando, se dedican a tejer y remendar sus redes; se juntan varios de ellos y comparten charlas y algunas bebidas refrescantes mientras avanzan en su tarea. Los niños van y vienen. Algunos de ellos se acercan al grupo de hombres y se interesan por aprender de sus padres a remendar las redes. Los padres quedan al cuidado de los niños, a cargo, además, de la socialización de conocimientos adquiridos en la práctica de la pesca, mientras las mujeres dedican ese tiempo a la organización y gestión de actividades comunitarias.

De igual forma, hay mujeres que salen a pescar con sus esposos, hijos, sobrinos o primos. Otras mujeres que son, al igual que algunos hombres, dueñas de canoas y sus respectivos motores, por lo que emplean a algún lugareño o llegadero como pescador. Es el caso de doña Narcisa Estupiñán Paredes, quien al ser una mujer soltera es quien emplea a su cuñado Piano Revelo Rengifo, esposo de su hermana Agustina, como pescador de su canoa con motor. A bordo, don Piano pesca en sus jornadas matutinas camarón titi, hediondita, sierra, lisa, pargo, ñato y bagre, entre otras especies que se encuentran en la bocana y sus alrededores.

Las vigieñas y mulateñas son mujeres fuertes que conocen el quehacer del pescador en ese ambiente y saben contribuir de esa forma en el hogar cuando la situación económica así lo requiere. Una mirada cercana expresa Paula Galeano al respecto:

Volviendo al tema de género, respecto a la flexibilización de roles en cuanto a la participación familiar en la actividad, en tiempos recientes han cambiado algunas prácticas; las mujeres han empezado a incursionar en las faenas de pesca por emergencia, pues no hay marineros ni proberos suficientes, además, si van miembros de una misma familia, el ingreso de la venta se queda allí mismo. Aunque continúa un predominio de género, ya no es tan automática la relación pesca de camarón-hombre, o recolección de concha-mujer ${ }^{28}$.

28 Galeano, Gestión desde la "diferencia”, 65. 
En el ámbito político, al igual que en el económico, el equilibrio entre mujeres y hombres también llega a ser palpable, pues a la cabeza de algunos de los asuntos políticos más importante para la Playa se encuentra doña Florinda Paredes, la figura femenina de mayor autoridad, quien en calidad de única representante de la Junta de Herederos que vive en Vigía, es una reconocida intermediaria frente a agentes estatales. Por ejemplo, doña Florinda se encarga de gestionar ante la administración pública del Charco los subsidios para vigieños y vigieñas de la tercera edad. De igual forma, es la persona encargada de hacer prevalecer aquellos principios de organización comunitaria pactados por los comuneros en su primer documento. Ella ha gestionado la creación de una Junta de Acción Comunal para la Vigía con el fin de que la Playa gane mayor autonomía en el manejo y disposición de los recursos provenientes del municipio de La Tola. Para tal propósito, ha contado también con la ayuda de una reconocida figura en la Vigía, don Miguel Revelo Rengifo, otro de los mayores de la Playa que ha gestionado, con agentes del Estado, mejores condiciones de vida para sus vecinos y familiares. Doña Manuela Estupiñán es otro ejemplo de mujer líder, pues es uno de los dos socios del cuarto frío de Vigía que también abastece a Mulatos y poblados aledaños, y es el centro de acopio de la producción pesquera e intermediario comercial con el puerto de Buenaventura. Lucía Estupiñán, "La Lucha", es la curandera de Playa Mulatos. Tiene prácticos conocimientos de enfermería, aprendidos en cursos tomados a distancia. Cabe anotar que el proceso de toma de decisiones que afectan a la comunidad sucede por un litigio deliberativo en el que mujeres y hombres participan por igual.

Las celebraciones y rituales que hacen parte de las festividades de la vida en comunidad de Vigía son organizadas y dispuestas logísticamente por las mujeres. Un grupo de cinco de ellas, que se hacen llamar "las vicarias", se dedican a la organización de las festividades religiosas que conmemoran los vigieños, como por ejemplo la fiesta de la Virgen del Carmen. Este grupo está encargado de la planeación de las Novenas para la virgen: en qué casas se rezará, los músicos para el arrullo en cada Novena, la presencia del sacerdote para la misa del 16 de julio y todos los requerimientos acordes a esta celebración eucarística, así como las lanchas o naves de las que se dispondrá para arrullar a la Virgen después de la misa del 16.

La fiesta mareña que se celebra a la Virgen del Carmen, Patrona del Mar, es una tradición que aparece en Playa Mulatos sin temporalidad conocida, que ha sido construida y formalmente instituida. Tal como lo afirma Eric Hobsbawm, la principal preocupación al reflexionar sobre la tradición no es su permanencia, sino su aparición y consolidación, más que sus posibilidades de supervivencia:

La tradición inventada implica todo un grupo de prácticas, normalmente gobernadas por reglas aceptadas abierta o tácitamente y de naturaleza simbólica o ritual, que buscan inculcar determinados valores o normas de comportamiento por medio de 
su repetición, lo cual implica automáticamente continuidad con el pasado. De hecho, cuando es posible, normalmente intentan conectarse con un pasado histórico que les sea adecuado $^{29}$.

En este orden de ideas, decisiones como la escogencia de las casas donde se harán las respectivas Novenas es un reconocimiento de estatus social y pertenencia al grupo socioparental. Debe ser una casa espaciosa que logre albergar al grueso de la Playa en su interior. Cada Novena está a cargo no solo del anfitrión de la casa que recibe a la Virgen, sino también de los vecinos del sector. Cada grupo se encarga de elaborar y decorar un altar con flores, velas y ramas de flora nativa para recibir en él a la Virgen. Disponen el espacio de la casa de tal manera que en el centro del salón se puedan ubicar los cantadores y los músicos con sus bombos y cununos, mientras que los asistentes se ubican alrededor de ellos. Los encargados también decoran la calle instalando arcos de papelillo que van marcando el camino por el que la Virgen hará su pasada acompañada de los pobladores que, al son de los alegres arrullos, la trasladan hasta su próxima parada.

Al llegar la noche, cuando la hora de la Novena se aproxima, los pobladores se reúnen en la casa que realizó la pasada y esperan en la calle hasta que el dueño de aquella le haga la entrega formal a los nuevos encargados de recibir a la Virgen, quienes la cargan y la trasladan en medio de una procesión hasta la casa en donde esa noche tendrá lugar la Novena y alojará a la Virgen hasta el otro día. Cuando la procesión llega a su destino, los músicos toman su lugar en el centro del salón, el resto de los asistentes se acomodan alrededor, permitiéndoles a los mayores sentarse en las sillas dispuestas. Don Alberto, el catequista en aquellas Novenas de 2011, se ubica frente a la Virgen y con el gesto de santiguarse da comienzo al rezo correspondiente a ese día.

Las siete casas escogidas para las novenas van formando un recorrido que es el paseo de la Virgen por todo el pueblo. Generalmente las novenas comienzan en el extremo de arriba de la Playa, el extremo sur, y terminan en una de las casas de abajo, en el extremo norte, más cercanas a la casa comunal y a la iglesia, donde el 15 de diciembre se acompaña a la Virgen durante toda la noche al ritmo de cantos y bailes de los arrullos, para el día siguiente celebrar la eucaristía respectivamente.

Transcurría el novenario de las festividades de la Virgen del Carmen en el 2011 y ya en el día quinto fue el turno de acoger a la Virgen en su casa para el rector de la escuela y su familia. Santiago Rodríguez, su esposa y sus tres hijos son una familia de padre negro y madre mestiza. La familia arribó a la Vigía luego de que él fuera nombrado rector del Centro Educativo de la Playa, pocos años atrás. Nunca había tenido esta familia la oportunidad de albergar en su casa a la Virgen y celebrar junto con toda la comunidad una Novena, así que en esa inédita ocasión la felicidad de on

29 Eric Hobsbawm, “Introducción: La invención de la tradición”, en La invención de la tradición, eds. Eric Hobsbawm y Terence Ranger (Barcelona: Crítica, 2002), 5. 
Santiago y su esposa era innegable, pues para ellos el reconocimiento recibido por parte de los vigieños, representado en la estadía de la Virgen en su casa, era un símbolo de aceptación. Una tradición que en Playa Mulatos ha permitido la cohesión social de la comunidad, pues cada vez participan más los llegaderos en estas celebraciones, articulándose a estas de manera organizada por los mecanismos diseñados por los lugareños para tal propósito.

Al respecto Annie-Marie Losonczy, con base en el modelo de "recursos no-materiales", que profundiza en las relaciones sociales que otorgan prestigio, autoridad o seguridad a los grupos de parentelas, afirma que las sociedades negras les otorgan un lugar privilegiado a los intercambios rituales de propiedades simbólicas en la construcción de un espacio sociopolítico entre los grupos locales ${ }^{30}$. Aunque Losonczy lo plantea desde su caso de estudio en el Chocó entre emberas y negros, tiene total pertinencia para el caso que, ilustrado a partir de la experiencia de don Santiago, nos ocupa en Vigía entre lugareños y llegaderos.

Los intercambios entre vigieños y llegaderos involucran a dos grupos que se reconocen como distintos y en esta medida los flujos de comunicación entre ellos marcan tanto sus límites culturales como los espacios de apertura mutua. Esta lógica de interacción construye identidades de frontera móviles, las cuales pueden ser interpretadas como la movilidad de un individuo o grupo por varias territorialidades, promoviendo una fluctuación constante de elementos culturales y transgrediendo las fronteras del territorio. Como consecuencia de estos intercambios, cada cultura impregna a la otra y al mismo tiempo permite ser permeada, pero conservando sus perfiles diferenciadores.

En definitiva, es posible afirmar que si bien los intercambios culturales y materiales como un aprendizaje mutuo fueron el vehículo que posibilitó la convivencia entre los llegaderos de las riberas cercanas y los vigieños, estos intercambios han estado matizados por una tensión latente que se manifiesta a través del discurso y en el acto de nombrar al otro, al igual que en algunas de sus principales prácticas culturales como la endogamia practicada por las familias de herederos. Por ejemplo, el mismo adjetivo de "culimochos", que es usado para definir a estos núcleos de población blanca, no es el nombre bajo el cual ellos se identifican a sí mismos. Esta categoría ha sido creada por los vecinos negros para resaltar que carecen de un trasero exuberante el cual no le hace juego a la rítmica mareña. Esta particular forma de nombrar resaltando lo que los negros podrían llamar un defecto de los blancos, según los antropólogos Jaime Arocha y Stella Rodríguez ${ }^{31}$, corresponde a un tipo de dinámica particular en la relación entre los "eurodescendientes" y los afrodescendientes que conviven en estos territorios.

$30 \quad$ Losonczy, "Memorias e identidad: los negro-colombianos del chocó".

31 Jaime Arocha y Stella Rodríguez, "Los culimochos: africanías de un pueblo eurodescendiente en el pacífico nariñense”, Historia Crítica diciembre (2003). 


\section{Comentarios finales}

Al considerarse como dueños legítimos de la tierra, la organización social que se llevó a cabo en Playa Mulatos estuvo definida también por la posesión de una Escritura Pública que para ellos legitimaba cualquier práctica o dinámica que sobre su playa se realizara, además de constituirse en un símbolo de diálogo y conocimiento del ordenamiento jurídico, el cual reconocía esta forma de propiedad. En este sentido, la defensa por el territorio pasaba también por la defensa de la legitimidad del título legal de propiedad, sustentada en la descendencia del linaje de los herederos y en el cumplimiento del conjunto de reglas formales e informales por parte de los lugareños. El control del territorio heredado logró garantizar, por medio de ciertas estrategias de control territorial, la reproducción y su relativa expansión; la memoria colectiva de los herederos fue instruyéndose permeada por esta forma de relacionarse con el territorio y de interactuar con otros grupos.

Ahora bien, los vigieños y mulateños heredan un título legal de propiedad del territorio por linaje, el cual han intentado perpetuar en su integridad a través de diferentes territorialidades a las que los herederos han dado vida a lo largo de su proceso de construcción territorial, autodenominándose comuneros de la Playa e institucionalizando unas reglas de convivencia entre ellos; practicando por siglos la endogamia cruzada; organizándose y participando políticamente en las instancias constitucionales reconocidas para interlocutar con el Estado colombiano en áreas protegidas y/o campos; y practicando a diario el arte tradicional de la construcción naval de fuertes embarcaciones que cubren las principales rutas marítimas de puerto a puerto. Así pues, estas y algunas de las estrategias de territorialización y acceso a los recursos construidas por los herederos, afirman y contrastan las territorialidades de las comunidades étnicamente diferenciadas del Pacífico, caracterizadas por los estudiosos del tema.

En definitiva, las fuentes orales y escritas que han hecho referencia a la Escritura y al documento de Las doce reglas de los comuneros, evidencian una estrategia de afiliación territorial distinta a las tres que Odile Hoffmann ${ }^{32}$ ha definido en su estudio sobre las estrategias de afiliación territorial en el Litoral Pacífico, a saber: 1) por filiación: ser nativo del lugar; 2) por alianza: unión conyugal; y 3) por presencia efectiva: ser residente del lugar. No obstante, una cuarta estrategia de afiliación territorial que sobrevive en el Pacífico colombiano y específicamente en el litoral Pacífico nariñense en Vigía y Mulato es el linaje, pues la forma legítima de afiliación a esta playa es ser descendiente de las familias de herederos. Es entendible que hasta ahora no se haya hablado de esta estrategia de afiliación territorial en el Pacífico si tenemos en cuenta que ninguno de los dos grupos étnicos identificados en esta zona, negros e indígenas, heredan un título legal de propiedad del territorio por linaje.

Hoffmann, "Territorialidades y alianzas: construcción y activación". 
Finalmente, el poseer una propiedad en el siglo XVIII no fue lo que en realidad les permitió a los vigieños y mulateños haber construido un proceso de territorialización distinto del de los negros e indígenas, ya que muchos de los negros esclavos que quedaron libres siguieron trabajando en sus propias minas o en minas sin dueño. Es, en definitiva, lo que cada grupo logró construir como territorio lo que diferencia sus procesos históricos. La historia de Vigía y Mulatos, así como otras tantas historias, han existido en silencio y siguen esperando que las descubramos.

\section{Bibliografía}

\section{Fuentes primarias}

Cadena, David. "Venta de derechos herenciales". Notaria 74 de Bogotá. [consultado el 8 de junio de 2016]. http://notaria74bogota.co/index.php/compraventas/derechos-herenciales.

Castellanos Díaz, Eliana. "Los armadores de barcos del Pacífico". El Espectador. 3 de marzo de 2002, No. 85.

"Escritura Pública de la propiedad sobre Playa Mulatos", Instrumento No.3, 1892, Archivo de Buga.

\section{Fuentes secundarias}

Almario, Oscar y Ricardo Castillo. "Territorio, poblamiento y sociedades negras". En Renacientes del Guandal. "Grupos negros” de los ríos Satinga y Sanquianga. Medellín: Ministerio del Medio Ambiente, Universidad Nacional de Colombia, 1996.

Arocha, Jaime y Stella Rodríguez. "Los culimochos: africanías de un pueblo eurodescendiente en el Pacífico nariñense". Historia Crítica 24, diciembre (2003): 79-95.

Baczkob, Bronislaw. Los imaginarios sociales. Memorias y esperanzas colectivas. Buenos Aires: Ediciones Nueva Visión SAIC, 1999.

Bhabha, Homi K. "El entre-medio de la cultura". En Cuestiones de identidad cultural, compilado por Stuart Hall y Paul du Gay, 94-106. Buenos Aires - Madrid: Amorrortu Editores, 1996. 
Bourdieu, Pierre. "La Tierra y las estrategias matrimoniales". En El sentido práctico, 235-256. Argentina: Siglo Veintiuno Editores, 2007.

Burke, Peter. Formas de historia cultural. Madrid: Alianza Editorial, 2000.

Camacho, Juana y Eduardo Restrepo. De montes, ríos y ciudades. Territorios e identidades de la gente negra en Colombia. Bogotá: Fundación Natura, Ecofondo, Instituto Colombiano de Antropología, 1999.

Castillo, Luis Carlos. "La construcción de la identidad del otro: poder y resistencia". En Etnicidad y nación. El desafio de la diversidad en Colombia, 31-92. Cali: Programa Editorial Universidad del Valle, 2009.

Galeano, Paula. Gestión desde la "diferencia" en áreas protegidas y territorios étnicos (consejos comunitarios). Apuntando al dialogo entre los biótico, lo cultural y lo político. Estudio de caso en el Parque Nacional Natural Sanquianga (Pacifico Sur Colombiano). Bogotá: Universidad Nacional de Colombia, 2005.

Hall, Stuart. "Introducción: ¿quién necesita $<<$ identidad $>>$ ?”. En Cuestiones de identidad cultural, compilado por Stuart Hall y Paul du Gay, 13-39. Buenos Aires - Madrid: Amorrortu Editores, 1996.

Hobsbawm, Eric. "Introducción: La invención de la tradición". En La invención de la tradición, editado por Eric Hobsbawm y Terence Ranger, 5-45. Barcelona: Crítica, 2002.

Hoffmann, Odile. "Territorialidades y alianzas: construcción y activación de espacios locales en el Pacífico". En De montes, ríos y ciudades. Territorios e identidades de la gente negra en Colombia, editado por Juana Camacho y Eduardo Restrepo, 75-93. Bogotá: Fundación Natura, Instituto Colombiano de Antropología, Ecofondo, 1999.

"La movilización identitaria y el recurso a la memoria (Nariño, Pacífico colombiano)". En Memorias hegemónicas, memorias disidentes, editado por Cristóbal Gnecco y Marta Zambrano, 97-120. Popayán: ICAN, Universidad del Cauca, 2000.

Losonczy, Anne-Marie. "Memorias e identidad: los negro-colombianos del chocó." En De ríos, montes y ciudades. Territorios e identidades de la gente negra en 
Colombia, editado por Juana Camacho y Eduardo Restrepo, 13-24. Bogotá: Fundación Natura, Instituto Colombiano de Antropología, Ecofondo, 1999.

Motta González, Nancy. Por el monte y los esteros. Relaciones de género y familia en el territorio afropacífico. Cali: Pontificia Universidad Javeriana, 2002.

Rivas, Nelly. "Modalidades de acceso a la tierra en el Pacífico nariñense: río Mejicano-Tumaco". En De montes, ríos y ciudades. Territorios e identidades de la gente negra en Colombia, editado por Juana Camacho y Eduardo Restrepo, 95-106. Bogotá: Fundación Natura, Instituto Colombiano de Antropología, Ecofondo, 1999.

Rodríguez, Stella. "Piel mulata, ritmo libre: identidad y relaciones de convivencia interétnica en la costa norte de Nariño, Colombia", tesis de pregrado, Universidad Nacional de Colombia, 2001.

. "Libres y culimochos: ritmo y convivencia en el Pacífico Sur colombiano". En Afrodescendientes en las Américas: trayectorias sociales e identitarias, editado por Claudia Mosquera, Mauricio Pardo y Odile Hoffmann, 313332. Bogotá: Universidad Nacional de Colombia, ICANH, IRD, ILAS, 2002. 